\title{
Review \\ Continuous simulation modelling for design flood estimation - a South African perspective and recommendations
}

\author{
TJ Rowe ${ }^{1 *}$ and JC Smithers ${ }^{1,2,3,4}$ \\ ${ }^{1}$ Centre for Water Resources Research, University of KwaZulu-Natal, Pietermaritzburg Campus, Private Bag X01, Scottsville 3209, South Africa \\ ${ }^{2}$ Bioresources Engineering - School of Engineering, University of KwaZulu-Natal, Pietermaritzburg Campus, Private Bag X01, \\ Scottsville 3209, South Africa \\ ${ }^{3} J$ G Afrika (Pty) Ltd, 6 Pin Oak Avenue, Hilton, Pietermaritzburg, 3201, South Africa \\ ${ }^{4}$ National Centre for Engineering in Agriculture, University of Southern Queensland, Toowoomba, Australia
}

\begin{abstract}
A number of severe flooding events have occurred both in South Africa and internationally in recent years. Furthermore, changes in both the intensity and frequency of extreme rainfall events have been documented, both locally and internationally, associated with climate change. The recent loss of life, destruction of infrastructure, and associated economic losses caused by flooding, compounded by the probability of increased rainfall variability in the future, highlight that design flood estimation (DFE) techniques within South Africa are outdated and in need of revision. A National Flood Studies Programme (NFSP) has recently been initiated to overhaul DFE procedures in South Africa. One of the recommendations in the NFSP is the further development of a continuous simulation modelling (CSM) system for DFE in South Africa. The focus of this paper is a review of CSM techniques for DFE, to guide further development for application in South Africa. An introduction to DFE, and particularly the CSM approach, is presented, followed by a brief overview of DFE techniques used in South Africa, leading into a more detailed summary of CSM for DFE within South Africa to date. This is followed by a review of the development and application of CSM methods for DFE internationally, with a focus on the United Kingdom and Australia, where methods have been developed with the intention of national scale implementation. It is important to highlight that there is a plethora of CSM methods available internationally and this review is not exhaustive; it focuses on and identifies some of the strengths and weaknesses of several popular methods, particularly those intended for national scale application, as the intended outcome from this review is to identify a path towards the development of a usable national scale CSM system for DFE in South Africa. Emphasis on a usable method is important, considering the reality that, despite promising results, numerous benefits, and national scale methods being developed, it appears that the CSM method for DFE is rarely used in practice.
\end{abstract}

Keywords: design flood estimation, continuous simulation, South Africa, SCS-SA and ACRU models, United Kingdom, Australia

\section{INTRODUCTION}

The assessment of flood risk by associating a flood event with a probability of exceedance or return period is the standard approach to design flood estimation (DFE) in most countries (Smithers, 2012; Kang et al., 2013). This is essential to the planning, prevention and control of the damaging effects of flooding to hydraulic infrastructure such as dams, bridges and culverts, and to development sites situated within the floodplain (Lamb et al., 2016).

DFE techniques for most countries can be categorised into two broad groups, which generally include: (i) approaches based on the statistical analysis of observed peak discharges, and (ii) rainfall-runoff simulation based on either event modelling or continuous simulation modelling (CSM) (Smithers, 2012). The approaches to DFE in South Africa are outdated and are in need of revision (Alexander, 2002; Görgens, 2007; Smithers, 2012; Van Vuuren et al., 2013). Consequently a National Flood Studies Programme (NFSP), aimed at updating and modernising the various approaches to DFE used in South Africa, has recently been proposed and initiated (Smithers et al., 2016).

\footnotetext{
* To whom all correspondence should be addressed.

욜 +27 71 493-1238;

e-mail: 209510188@stu.ukzn.ac.za
}

Received 27 November 2017, accepted in revised form 25 September 2018
Alexander (2002) highlighted the need to update DFE procedures, after severe flooding in southern Africa in 1999 and 2000, and this was supported by Smithers (2012) after flooding in the Western Cape in 2005 and in the Free State and Eastern Cape in 2011. A recent review of flooding events reported in FloodList (2016) highlighted several large flood events across the globe in 2016 including, inter alia, Germany, Romania, China, Paris - France, the Ukraine, the United States, Belgium and Russia. Several of these floods at specific locations exceeded previous records (FloodList, 2016). Furthermore, a recent report by the United Nations (UN) states that over the past 20 years (1995-2015), approximately 157000 people have died as a result of flooding, with a further 2.3 billion people affected by the damaging effects of flooding over the same period (UNISDR, 2015). According to the United Nations Office for Disaster Risk Reduction (UNISDR, 2015), flooding accounts for approximately $56 \%$ of weather-related disasters, with the remaining $44 \%$ accounted for as follows: drought $\approx 26 \%$, storms $\approx 16 \%$, extreme temperatures, landslides and wildfire $\approx 2 \%$. South Africa has also experienced recent flooding with floods reported in and around Durban (July, 2016), with record-breaking rainfall depths, 5 deaths, and damages totalling millions of Rands (FloodList, 2016). During the same period the Western Cape experienced floods that affected more than 10000 people, as reported by local disaster management officials (FloodList, 2016). 
The recent flooding emphasises the need to update DFE methods in South Africa, further motivated by evidence and projections of possible changes in both the intensity, frequency and seasonality of extreme rainfall events in South Africa, i.e., as a result of human-induced climate change (Ndiritu, 2005; Kruger, 2006; Du Plessis and Burger, 2015; Kruger and Nxumalo, 2017). Hrachowitz et al. (2013) and Kusangaya et al. (2014) also allude to such phenomena, where alterations in rainfall patterns, and an increased prevalence and intensity of natural hazards, has been observed. This adds an additional dynamic to DFE that needs to be accounted for and the CSM approach has significant potential to accommodate such scenarios, i.e., changing input data and model parameters to simulate future flood characteristics. These include, for example, changes in rainfall patterns, local climate, land cover and catchment physiographical changes (Lamb et al., 2016; Vogel, 2017). This is a significant advantage of the CSM approach to DFE over approaches based only on the analysis of observed runoff, with the inherent assumption of stationarity and the extrapolation of higher return period floods based on the limited number of observed records available (COST, 2013).

The origins of CSM date back to the late 1950s with the Stanford Watershed Model, the first computer-based continuous hydrologic simulation model developed (Crawford and Burges, 2004). The method evolved over the period from 1959 to 1974 , and led to the development of the computer code known as the Hydrologic Simulation Program Fortran (HSPF), produced for and with the support of the United States Environmental Protection Agency - USEPA (Crawford and Burges, 2004). Since then continual development, motivation for, and experimentation with the CSM approach to runoff simulation has been documented within the literature, as reviewed in this paper, and has resulted in the plethora of currently available continuous simulation (CS) rainfall-runoff models. The benefits of the CSM approach to DFE over traditional event-based rainfall-runoff techniques include the ability of the method to account for: (i) constant and changing catchment characteristics (e.g. land cover and climate), (ii) the impact of antecedent soil moisture conditions on runoff generation, and (iii) a more comprehensive representation of hydrological processes. Lamb et al. (2016) provides additional examples of the benefits of a CSM approach and case studies where the CSM approach has been applied in practice to problems too complicated to be adequately assessed with the event-based or statistical methods available in the United Kingdom, further details of which are provided later in this paper.

The CSM approach, like many of the rainfall-runoff methods used in South Africa, is generally applicable to small catchments $\left(<50 \mathrm{~km}^{2}\right)$. According to Smithers et al. (2016), the majority of the catchments (55\%) for which design floods are required in South Africa are relatively small $\left(<15 \mathrm{~km}^{2}\right)$. Therefore, based on the advantages of the CSM approach, as alluded to above, and as reviewed in detail throughout this paper, the benefit of developing a CSM methodology for DFE in small catchments, applicable at a national scale in South Africa, is highlighted. In addition, comparison of this method to alternative event-based, empirical and statistical methods may then be performed.

In this paper, the use of CSM for DFE is critically reviewed, both within South Africa and internationally. The objective of the review is to: (i) outline the general framework and options available when implementing a CSM approach for DFE, (ii) summarise the developments towards a CSM approach to DFE in South Africa, and (iii) identify approaches from the international literature which could be used in the further development of a CSM approach for South Africa. The international review is focused on two countries, namely, the United Kingdom and Australia. These countries are at the forefront in terms of flood research internationally, with both countries recently revising the techniques and methodologies applied to estimate design floods at a national scale. The literature review is followed by a discussion of the review relevant to further development of a CSM system for DFE in South Africa.

\section{GENERALISED FRAMEWORK FOR CONTINUOUS SIMULATION MODELLING}

This section will briefly describe the general framework towards implementation of a CSM approach to DFE, including the various steps, options and associated models that may be incorporated into the approach. In general, a CSM approach requires time-series inputs of climate data such as rainfall and evapotranspiration. At a bare minimum, however, rainfall data is essential for all CS models, and the quality of the data is of upmost importance as the rainfall is the main driver of runoff production. Depending on the CS model selected, these inputs may be required at various time-steps from daily or hourly, to sub-hourly. In general, the finer the resolution of the time-step the sparser the availability of data. In terms of rainfall data, daily rainfall values are more readily available and are of longer record length (Smithers and Schulze, 2000; Grimaldi et al., 2012).

In the simplest case, observed rainfall records of suitable length, if available, may be used directly as input to a CS model to obtain an output of simulated flow time-series. In many cases, however, long records of rainfall within a region may not be available or the records are relatively short. This is a particularly large problem when estimating design floods, where long records are needed to obtain more reliable and accurate estimates of flood quantiles at the higher return periods.

For this reason stochastic rainfall generators are commonly used with CS models, as well as many other rainfall-runoff simulation-based approaches, to generate or extended rainfall records (e.g. Beven, 1987; Smithers et al., 2000; Clothier and Pegram, 2002; Frezghi, 2005; Sivapalan et al., 2005; Rogger et al., 2012; Sharma et al., 2016; Arnaud et al., 2017; Odry and Arnaud, 2017). Similarly, rainfall disaggregation models, or simple disaggregation techniques, are also commonly applied to generate short duration data from longer time-steps, e.g., daily to hourly (Calver et al., 2005; Knoesen, 2005; Knoesen and Smithers, 2009; Grimaldi et al., 2012; Haberlandt and Radtke, 2014; Nathan and Ling, 2016). Therefore, a plethora of rainfall generation as well as disaggregation models has been developed and implemented with CSM approaches internationally, with limited experimentation in South Africa as reviewed in the next section. An exhaustive review on these methods is not provided in this paper, since the focus is on the CS rainfall-runoff models themselves, based on the following reasoning. It is believed that developing a robust CS model that can be validated using actual observed rainfall and runoff data is a critical first step and, once validated, further system development such as rainfall generators or disaggregation techniques should be considered, since they provide significant benefit in terms of extending rainfall record lengths and plausible sequences of events not evident in the observed record. Furthermore, it should be noted that an additional source of uncertainty is introduced when incorporating these stochastic and disaggregation rainfall models. The significant value and potential of these techniques, 
however, is acknowledged, and further implementation and development of these approaches is recommended, and should likely be included in all simulation-based approaches in South Africa in the future. This may become more critical if the trend of diminishing hydrological data networks, as identified by Wessels and Rooseboom (2009) and Pitman (2011) and which is persisting in South Africa, continues. It should be noted, however, that a national database with 50 years of rainfall, temperature, Apan evaporation and other climate variables is available in South Africa, and has been used extensively with the ACRU model for various water resource management applications (Smithers and Schulze, 2004), including DFE as reviewed in the following section. Ideally, the availability of a database of observed rainfall, estimated evaporation and observed runoff is required for CS model development and verification as this enables the CS model to be used with confidence in stochastic simulations. Thereafter the use of stochastic rainfall models provides additional benefits, including: (i) extending the length of rainfall records and uncertainty estimation with an ensemble or Monte-Carlo type approach (Weinmann et al., 2002; Nathan and Weinmann, 2013; Nathan and Ball, 2016; Nathan and Ling, 2016), i.e., generating thousands of rainfall time-series to simulate thousands of runoff time-series to obtain a range of possible simulations, and (ii) accounting for the effects of climate change by incorporating these scenarios into the models (Lamb et al., 2016; Vogel, 2017).

Another important component of both stochastic rainfall models and CS rainfall-runoff models is parameter calibration. In most cases model parameters are calibrated against observed data, i.e., parameters are optimised until the best fit between the simulated and observed data is obtained, which is assessed using an objective function such as the root mean squared error (RMSE) or the Nash-Sutcliffe efficiency (NSE) (Blöschl et al., 2013). A regionalisation approach is required to estimate the model parameters at ungauged locations. Several regionalisation techniques are available such as spatial proximity and similarity pooling, a region-of-influence type approach, regression-based methods or cluster analysis (Smithers, 2012; Blöschl et al., 2013; COST, 2013; Odry and Arnaud, 2017). In the case of the ACRU model in South Africa direct calibration of model parameters is not performed (Schulze, 1995). Model parameters are linked to physical catchment characteristics, and observed data is only used to verify the model simulations. Consequently, the need for direct regionalisation of parameters is not necessary, although parameters may be derived from catchment characteristics which do vary regionally, therefore regionalisation approaches are not a focus of this paper. The advantage of the physicalconceptual nature of the ACRU model, with parameter values generally linked to catchment characteristics, is that the structure of the model and process representations are based on an increased knowledge and understanding of hydrological processes and their interactions at various scales (Schulze, 1995). Hrachowitz et al. (2013) believe that this is essential to improve predictions in ungauged basins, and Lamb et al. (2016) highlights this as one of the greatest advantages of the CSM approach.

When using a CSM approach for DFE, a standard flood frequency analysis (FFA) is performed by fitting a suitable probability distribution to the annual maximum series (AMS) or a peak over thresholds (POT) series extracted from the simulated flows (Ball, 2013; Ling et al., 2015). Alternatively, a direct frequency analysis on all flows may be performed (Lamb et al., 2016). The FFA can be performed to estimate both flood volume and peak discharge quantiles. In most cases these estimates are required as input to a hydraulic model, or a flood routing model, for floodplain delineation or the design and management of hydraulic structures and systems (Lamb et al., 2016). Hydraulic modelling is then performed to determine the inundation levels of the flood based on flood peak, volume and full flood hydrographs (Lamb et al., 2016). The advantage of a CSM approach is that a coherent set of all three components is simulated by the model (Lamb et al., 2016). Odry and Arnaud (2017) highlight that statistical FFA methods often estimate flood volumes and peak discharges independently, and therefore the joint association between peaks and volumes is not maintained. In addition, other event-based methods such as the rational method only estimate peak discharges (Smithers, 2012). In summary, hydrological outputs from any FFA method are often used as direct inputs to hydraulic models such as HEC-RAS, e.g., as used extensively by the South African National Roads Agency Limited (SANRAL, 2013). Hydraulic modelling of floods is not reviewed in great detail in this paper since the focus is on the CS models applied; however, a final significant benefit of the CSM approach that is worth highlighting is that complete time-series, or at least the largest events above a threshold may be input, or directly linked to, a hydraulic model, e.g., to simulate multiple inundation levels that are directly associated with the individual events simulated by the CS model, and a FFA may then be performed on the flood levels simulated by the hydraulic model. Ultimately the DFE method selected is dependent on the type of problem or project under investigation, as well as practical constraints such as budget and time. The CSM approach, however, is one of the most comprehensive methods available.

\section{DESIGN FLOOD ESTIMATION IN SOUTH AFRICA}

A number of approaches to design flood estimation have been developed for application in South Africa. This section provides a brief overview of the approaches and then focuses on the use of continuous simulation modelling.

\section{Overview of approaches}

Smithers (2012) and Smithers et al. (2013) categorise DFE techniques used in South Africa into two groups: (i) the analysis of observed flow data, and (ii) rainfall-runoff based methods, as shown in Figure 1.

Detailed reviews of the various methods for DFE in South Africa are provided in, inter alia, Smithers (2012), SANRAL (2013) and Rowe (2015). Many of the methods, however, are outdated and consequently a NFSP, aimed at modernising and updating the various approaches to DFE within South Africa, has been initiated (Smithers et al., 2016). The focus of this study is on the rainfall-runoff CSM approach, one of the methods recommended for development in the NFSP. Consequently, the next section contains a review of the developments towards a CSM approach for DFE in South Africa.

\section{Continuous simulation modelling and associated developments}

In South Africa reasonable results have been obtained from the successful application of the CSM approach for DFE in a number of pilot studies (Smithers et al., 1997; Smithers et al., 2001; Chetty and Smithers, 2005; Smithers et al., 2007; Smithers et al., 2013). The CS model used in all these studies was the physically-based, conceptual, daily time-step ACRU 


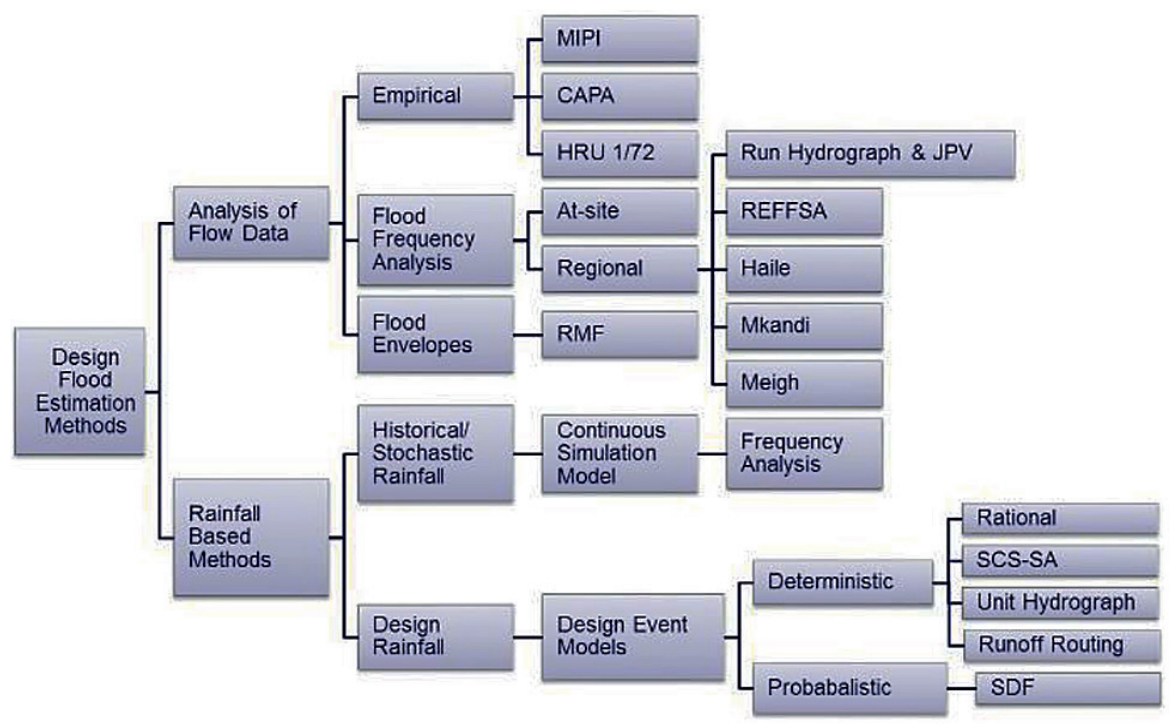

Figure 1

Design flood estimation methodologies within South Africa (after Smithers, 2012)

agrohydrological model (Schulze, 1995). The model, developed at the University of KwaZulu-Natal (formerly the University of Natal) in South Africa, has been extensively verified and accepted for a range of practical water resource management applications, including experimentation as a tool for DFE in several pilot studies, as alluded to above (Schmidt and Schulze, 1987; Schulze et al., 2004; SANRAL, 2013). A brief description and summary of the investigations performed in some of these pilot studies is presented below. However, for further details of the investigations and results refer to Smithers et al. (2001); Smithers et al. (2007); Smithers et al. (2013) and Rowe (2015).

Smithers et al. (2001) performed a range of assessments on the extreme rainfall and flooding experienced over the north-eastern parts of South Africa, Mozambique and Zimbabwe during the February 2000 floods caused by tropical depressions and cyclone activity, using the Sabie River catchment upstream of the South Africa/Mozambique border as a case study $\left(6260 \mathrm{~km}^{2}\right)$. The ACRU CS model was used to validate the peak discharge estimates derived from surveyed flood lines and hydraulic calculations (Van Bladeren and Van der Spuy, 2000), i.e., since the exceptional flooding resulted in the failure and destruction of several gauging stations (Van Biljon, 2000) and therefore no observed flow data was available at many gauging stations. Furthermore, the primary runoff data for many of the gauges in the catchment were found to be unreliable due to flows regularly exceeding the rating capabilities of these structures, and consequently the ACRU model was used to simulate runoff and peak discharges over these periods (Smithers et al., 2001). The importance of using a CSM approach in this case lies in the ability of the method to explicitly represent antecedent soil moisture conditions during the build-up to the events that produced the highest peaks, where it was highlighted that antecedent conditions played an important role in the severity of the events. In addition, the ability to model the catchment in distributed mode and consequently account for the nonuniformity of rainfall was necessary, i.e., since the rainfall and hence flooding, was spatially considerably variable within the catchment. The modelling in distributed mode also required flood routing, all of which the CSM approach could provide
(Smithers et al., 2001). The ACRU simulations for the February 2000 events were in close agreement with the hydraulically derived estimates of Van Bladeren and Van der Spuy (2000), i.e., where observed estimates were not available. Comparison of the observed and simulated flood frequency curves (FFCs) for gauges that had adequate observed data highlighted that the simulated results closely mimicked the observed data, particularly for the higher return period events. In addition the spatial variability of the rainfall and flooding, in terms of magnitude and their associated return period at different points in the catchment, for the February 2000 events could be adequately represented and mapped using the ACRU simulated results (Smithers et al., 2001).

Smithers et al. (2007) and a summary paper by Smithers et al. (2013), present the results of several research projects that have contributed to the development and application of the ACRU modelling system for DFE. These refinements and developments to the ACRU modelling system were incorporated into the ACRU model by Smithers et al. (2007) and the methodology assessed using the Thukela Catchment $\left(29036 \mathrm{~km}^{2}\right)$ in South Africa as a case study.

The results highlighted the difficulty associated with applying the model to an operational catchment, i.e., where land cover changes and water abstractions occur and are not documented. Verification was further complicated by errors in observed data, sparse rain-gauge networks and problems with rating tables (Smithers et al., 2013). In summary, the results indicate that disaggregating catchments into smaller homogeneous subcatchments or hydrological response units (HRUs) is required and that area-weighted soils and land cover information, rather than lumped information, produced more realistic results. The benefit of using a representative driver rainfall station for each subcatchment, as opposed to a single driver rainfall station for the whole catchment, was also evident. The importance of extended historical rainfall records and accurate land cover information was also identified.

Frezghi (2005) assessed the stochastic, fine-resolution space-time String-of-Beads Model (SBM) developed by Clothier and Pegram (2002) to simulate long series of rainfall over a catchment. This was done in order to more reliably estimate 
design floods. Frezghi (2005) concluded that the SBM may be used in rainfall-runoff modelling, including continuous simulation models, at detailed spatial and temporal scales, provided the SBM is appropriately calibrated (Smithers et al., 2013). At this point, it is important to mention that additional experimentation with different stochastic rainfall models in South Africa has been performed (e.g. Zucchini et al., 1992; Smithers and Schulze, 2000; Smithers et al., 2000; Smithers et al., 2002). Smithers and Schulze (2000), for example, assessed the performance of two variations of the Bartlett-Lewis rectangular pulse type of intra-daily stochastic models to estimate short-duration design rainfall in South Africa, and found the methods performed reasonably well when calibrated to both short duration data and daily data.

In addition to the stochastic model assessed by Frezghi (2005), a method to disaggregate daily rainfall into hourly totals in South Africa was developed and evaluated, in order to improve the shape of simulated hydrographs and the estimation of peak discharge. This was achieved using a regionalised semi-stochastic daily rainfall disaggregation model developed by Knoesen (2005). The model performed reasonably well with some suggestions to further refine certain aspects of the model (Smithers et al., 2013).

Further research on the temporal distribution of rainfall, methods to stochastically generate rainfall over a catchment, improvement to the estimation of catchment response times, and further development of flood routing methods for application in ungauged river reaches was also suggested. Ultimately, however, the results of Smithers et al. (2007), and summary of the results by Smithers et al. (2013), highlight the potential of the ACRU CS model to reproduce reliable and consistent estimates of design floods. Although promising results have been obtained, no CSM methodology has been developed to be applicable at a national scale, such as is available for the event-based SCS-SA model. Consequently, Rowe (2015) initiated preliminary investigations towards the development of a national scale CSM methodology for DFE within South Africa using the ACRU model.

Rowe (2015) highlighted that the ACRU model uses the same SCS (1956) runoff equation as the SCS-SA event-based model (Schmidt and Schulze, 1987) to estimate stormflow. There are, however, significant differences in model structure and how the parameters of the runoff equation are estimated, particularly the potential maximum soil water retention, or the soil water deficit $(S)$. In the SCS-SA model $S$ is estimated using a single parameter, the catchment curve number $(C N)$, which accounts for soil properties, land cover, land management, hydrological condition and antecedent soil moisture content. Initial CNs may be adjusted to account for the antecedent soil moisture conditions. The median condition and joint association methods (Schmidt and Schulze, 1987), which used the ACRU soil moisture budgeting routines to estimate the antecedent conditions for a 30-day period prior to large rainfall events, were a major improvement to the original moisture adjustment procedure introduced into the original SCS (1956) model. Therefore, the ACRU CSM approach has significant potential in improving the estimation of losses in event-based methods such as the SCS-SA model. Consequently, further development of the ACRU CSM approach provides the opportunity to update and possibly revise the SCS-SA soil moisture adjustment techniques.

Rowe (2015) also noted that there is value in the $C N$ in terms of accounting for the strong effects of soil and land cover properties on runoff generation. In addition, it was identified that the SCS-SA land cover classification accounts for different land management practices and hydrological conditions, which are not explicitly accounted for in the current ACRU land cover classifications. Consequently, Rowe (2015) undertook a study to determine how to represent land cover classes, as represented within the SCS-SA classification (Schulze et al., 2004), within the ACRU model. This was achieved by using the design runoff volumes simulated by the SCS-SA model as a surrogate for observed data. The differences in design runoff volumes simulated by the SCS-SA model were used as a reference to simulate similar design runoff volumes and changes in design runoff volumes with the ACRU model, applying the following steps:

(i) Attempts were initially made to achieve equivalence of soil representations between the SCS-SA and ACRU models, i.e., how to represent SCS-SA soil groups A-D in ACRU. Three attempts were made using soil textural properties to represent SCS-SA soil groups; however, it was found that SCS-SA soil groups could not be represented in the ACRU model by soil textural properties alone.

(ii) Consequently, a sensitivity analysis of several ACRU parameters was conducted in order to identify which ACRU parameters to use to represent SCS-SA soils and $\mathrm{CNs}$ best, for selected land cover classes.

(iii) Two ACRU parameters namely, QFRESP, a quick flow response coefficient which partitions stormflow into a same-day response fraction and a subsequent delayed stormflow response, and SMDDEP, which determines the critical hydrological response depth of the soil, were identified as sensitive parameters suitable to represent SCS-SA soils and land cover classes.

(iv) Through manual calibration QFRESP and SMDDEP values corresponding to a SCS-SA soil group and land cover class were identified to represent that land cover class in ACRU, i.e., by adjusting the QFRESP and SMDDEP parameters in the ACRU model until similar runoff volumes to those simulated by the SCS-SA model were obtained for a similar land cover in ACRU.

A strong relationship between these ACRU parameters and $C N$ values for selected SCS-SA soil groups and land cover classes was found and consequently preliminarily rules and equations were developed to represent SCS-SA land cover classes in ACRU (Table 8.1: Rowe, 2015).

The following recommendations were made to further validate and verify the approach and to further the development of a CSM system for DFE in South Africa (Rowe, 2015):

(i) The rules and equations derived from the experimentation with 3 land cover classes (veld/grassland, row crop/maize, small grain/wheat) were tested on a single land cover class, sugarcane. Therefore, only 4 land cover classes within the SCS-SA classification, out of a total of 9 , were investigated. Consequently, the rules and equations derived in the study were identified as preliminary best estimates, with further investigation and validation of the approach being required including:

- The analysis of additional land cover classes

- Further independent verification at different geographical locations

- Verification of the simulated results against observed data, in terms of both runoff volumes and peak discharges

(ii) Land cover information, based on the Acocks (1988) natural land cover map, needs to be updated with current actual land cover information.

(iii) The development of a CSM system or methodology is needed, i.e., how the system will be compiled or packaged for use at a national scale within South Africa. 
Verification of the simulated results in terms of peak discharges, i.e., in addition to runoff volumes, is important as flood peaks are typically required for the design of hydraulic infrastructure. Due to the large variability in the runoff response of catchments to storm rainfall, peak discharge estimation, particularly in ungauged catchments, continues to be a challenge in the field of hydrology both within South Africa and internationally (Gericke and Smithers, 2014). Catchment response time parameters, which impact directly on the hydrograph shape and peak discharge, are generally required as a primary input to most rainfall-runoff methods, including the CSM approach. The most frequently used catchment response time parameters are the time of concentration $\left(T_{C}\right)$, time lag $\left(T_{L}\right)$ and time to peak $\left(T_{P}\right)$ (Gericke and Smithers, 2014).

From a review of methods used both locally in South Africa and internationally to estimate catchment response time parameters, Gericke and Smithers (2014) identified inconsistencies between the methods, i.e., when compared to the recommended methods for South Africa, which were also shown to be used outside of the boundaries (location and catchment area) used to develop the methods. Identifying the need for an alternative, improved and consistent approach to estimate catchment response time, Gericke and Smithers (2016); Gericke and Smithers (2017); and Gericke and Smithers (2018) developed regionalised empirical equations to estimate catchment response times, expressed as the time to peak discharge (TP). The new empirically derived time parameter equations were tested on 4 climatologically different regions within South Africa and the results indicate that the method provides improved peak discharge estimates at ungauged catchments within these specific regions. Further development of the method to extend applicability to a national scale is recommended (Gericke and Smithers, 2016; Gericke and Smithers, 2018). Gericke and Smithers (2016) recommended that the improved methodology be included in both eventbased and CSM DFE methods in South Africa in order to obtain improved peak discharge estimates. Therefore, the inclusion of the new methodology for estimating catchment response time needs to be incorporated in the development of a CSM approach to DFE in South Africa.

The above brief review indicates that some progress has been made towards a CSM approach for DFE in South Africa. However, it is evident that there is still much work to be done to develop a comprehensive CSM methodology for DFE applicable at a national scale. The following sections review CSM developments from the international literature.

\section{DESIGN FLOOD ESTIMATION IN THE UNITED KINGDOM}

The Flood Studies Report (FSR) published by the Natural Environment Research Council (NERC, 1975) is the original guideline for flood estimation within the United Kingdom. This guideline was succeeded by the Flood Estimation Handbook (FEH) published by the Institute of Hydrology (1999). The FEH and its subsequent updates are extensively utilised to estimate design floods within the United Kingdom. Several statistical methods are available based on the analysis of observed streamflow data, using both at-site and regional approaches (Kjeldsen, 2015). In addition to the statistical approaches to DFE, an event-based FSR rainfall-runoff method (NERC, 1975) and subsequent updates, termed the FSR/FEH rainfallrunoff method, is included in the FEH, and is widely applied to generate hydrographs and peak flows (Kjeldsen, 2007; WHS,
2016). The FSR/FEH Revitalized Flood Hydrograph - ReFH (and updated ReFH2) rainfall-runoff model is made-up of: (i) a loss model, based on the uniform Probability Distributed Model (PDM) of Moore (1985) which is used extensively in the United Kingdom for a variety of hydrological applications, (ii) a routing model, using the commonly applied unit hydrograph (UH) concept, and (iii) a baseflow model, based on a linear reservoir concept (Kjeldsen, 2007). In addition to the widelyused event-based approach, several case studies report on the application of CSM approaches to DFE, as reviewed next, followed by a review of a national CSM method for application in the United Kingdom.

\section{Continuous simulation modelling - case studies}

Calver and Lamb (1995), Calver (1996), Calver et al. (1999), Cameron et al. (1999), Lamb (1999), Calver et al. (2004) and Calver et al. (2005), amongst others, have expended considerable effort towards the development of a CSM approach for flood frequency estimation in the United Kingdom.

The research of Calver and Lamb (1995), up to and including the development of a national CSM approach by Calver et al. (2005), has focused on national scale assessments and consequently simple parameter-sparse models have been selected, i.e., since parameters need to be derived indirectly from easily obtainable catchment descriptors. Calver et al. (2004), however, emphasise that more detailed parameterintensive CSM models are available for catchment-specific investigations. Such examples include the following models: (i) the Topography-Based Model of Catchment Hydrology (TOPMODEL) to simulate continuous flow series within the Generalised Likelihood Uncertainty Estimation (GLUE) framework, as implemented by Cameron et al. (1999), Cameron et al. (2000) and Cameron (2006), (ii) the Systeme Hydrologique European (SHE) model (Boughton and Droop, 2003; Devi et al., 2015), and (iii) the Hydrological Simulation Model (HYSIM) used widely in the UK water industry including the Environment Agency, as well as application in several other countries (WRA, 2018). A modified version of TOPMODEL within the GLUE framework has also been implemented in the Czech Republic by, inter alia, Blazkova and Beven (2004) and Blazkova and Beven (2009). Although such models are a significant development towards representing and understanding the various components of catchment hydrology, they are generally too complex and parameter-intensive for national scale application and are consequently restricted to application in small research catchments (Boughton and Droop, 2003). Calver and Lamb (1995) identified two suitable simpler models, namely the 5-parameter PDM (Moore, 1985) and the 3-parameter Time-Area Topographic Extension (TATE) Model (Calver, 1996), as applicable models to simulate continuous flow series, from which FFCs may be derived.

Calver and Lamb (1995) assessed the performance of these two simpler models on 10 catchments in the United Kingdom, ranging in size from $1 \mathrm{~km}^{2}$ to over $400 \mathrm{~km}^{2}$ with a range of geographical and topographical characteristics. Flood frequencies for both the observed and simulated flows, derived using a partial duration series approach, were also compared and discussed. The results fell within an acceptable range; however, some areas where improvements were needed were identified. It was noted by Calver and Lamb (1995) that data errors, even in a single hourly value of nominally qualitychecked data, can exert undue influence on the results. 
With regards to data, both Calver and Lamb (1995) and Calver et al. (2004), acknowledge that obtaining large data samples of suitable accuracy and record length, especially at sub-daily time scales, is challenging even in a relatively datarich country such as Britain. This highlights the importance of observed rainfall and streamflow records and is an observation worth noting with regards to the South African context where, as already mentioned, the number of observed rainfall and flow gauging stations is on the decline (Wessels and Rooseboom, 2009; Pitman, 2011)

Following the investigation of Calver and Lamb (1995), Calver et al. (1999) continued to experiment with the CSM approach to DFE and produced a 'pilot' flood frequency system for Britain using 35 catchments. The research around the CSM approach to DFE culminated in the development of a national CSM river catchment flood frequency method for the United Kingdom (Calver et al., 2005), as reviewed in the next section.

\section{Continuous simulation modelling - national approach}

Calver et al. (2005) report on the development of a national river catchment flood frequency method using CS, where 119 datarich catchments were used to extend the method developed by Calver and Lamb (1995), Calver et al. (1999) and Calver et al. (2001), to include full spatial coverage across Britain. The two models selected remained the TATE and PDM models, which had a proven track record of suitable performance.

At the onset, Calver et al. (2004) and Calver et al. (2005) highlight the advantage of working with data records of smaller time steps, to preserve the definition of flood peaks, where even a simple uniform disaggregation of daily rainfall into hourly totals provided superior results compared to direct use of the daily data. In addition, the benefit of extended records is also emphasised, i.e., to extend the estimation of floods to higher return periods. In terms of model calibration, a twopass sequential method of automatic calibration was adopted. Quantitatively, for all 119 sites investigated the mean absolute percentage errors between simulated and observed FFCs, for return periods from 1 to 20 years, ranged from $5-11 \%$ for the TATE model, and 4-9\% for the PDM model. Calver et al. (2005) noted that there was no obvious advantage of one model over the other. Furthermore, there was no obvious dependence of calibration performance on catchment properties; however, relationships between calibrated parameter values and catchment properties were identified. This demonstrated the potential for spatial generalisation of parameter values, required to estimate flood frequencies for all catchments in Great Britain, which includes a large proportion of ungauged catchments.

Calver et al. (2005) investigated and compared 3 different spatial generalisation techniques and noted that for each model the best-performing method provided mean percentage errors 2 to 3 times greater than those obtained from the calibration procedure. Calver et al. (2005) accounted for 2 sources of uncertainty related to: (i) the spatial generalisation procedure, and (ii) the calibration procedure. The uncertainty measures were used by Calver et al. (2005) to determine uncertainty bounds around each of the generalised FFCs for each catchment, i.e., treating them as ungauged. The uncertainty bounds were calculated for the 90, 95 and $99 \%$ confidence intervals to better illustrate the asymmetry and spread of the bounds. Quantitatively, the average 50 -year return period range of possible flood peak values, at the $99 \%$ confidence interval, ranged from between 1.75 to 2.17 times greater than the generalised estimate for both models at the upper bound and between 2.26 to 3.27 times greater for the lower bound. Therefore, there is considerable uncertainty around the generalised flood peak estimates. Calver et al. (2005) also noted that the uncertainties associated with data and model structure, which were not investigated in the study, may also be estimated, and are additional sources of uncertainty to consider.

\section{National CSM system versus FEH methods and recommendations}

Calver et al. (2005) compared the performance of the CSM approach to the FEH event-based methods, i.e., the ReFH rainfall-runoff model and the statistical method, i.e., using at-site data or a regional approach. The comparison is purely qualitative and included some of the following (Calver et al., 2005):

(i) The FEH and former FSR methods are generally preferentially applied compared to the CSM approach because they are relatively easier to apply, are well established and well defined, and practitioners are familiar with the approaches and understand how to use them. Furthermore, the methods are less data intensive.

(ii) Therefore, the aim of the study was to develop a comprehensive method and the required software, i.e., including data requirements, within a user-friendly interface, to allow users to obtain results promptly while still providing results with high accuracy, the intent being to facilitate and promote adoption of the CSM approach in practice.

(iii) The CSM approach is superior due to the continuous accounting of antecedent soil moisture, and the consequent joint probability analysis between rainfall and antecedent conditions.

(iv) The CSM approach is applicable to a larger range of catchment sizes, provided a distributed model setup is implemented.

(v) Furthermore, with respect to return period, it was highlighted that the CSM approach is generally restricted to estimates of lower return periods due to data availability; however, it is noted that this may be extended using stochastic data generation techniques.

(vi) Lastly, in terms of stationarity, the FEH methods assume a stationary climate and catchment conditions. The CSM approach, although calibrated against observed data with the assumption of stationarity, can simulate changes in climate or catchment conditions through the alteration of model parameters and inputs.

In general, recommendations included further testing and validation of the approach and methods developed. Possible variations to the methods need to be developed based on assessment and feedback from testing of the approach. In addition, quantitative comparison of the approach to the FEH methods is emphasised. Packaging of the approach into software and dissemination and adoption of the approach in practice is necessary. Detailed research on stochastically generated time-series is recommended, with strong emphasis on uncertainty estimates and the accuracy of the methods tested or investigated. In summary, Calver et al. (2004) and Calver et al. (2005) suggest that considerable effort is still needed to establish a national CSM method for flood frequency analysis (FFA) at ungauged catchments in the United Kingdom. The potential of the approach, however, is emphasised, and Calver et al. (2004) noted that addressing these challenges and improving the CSM approach is at the forefront of modelling research.

Since the publication of the national CS flood frequency method for the United Kingdom by Calver et al. (2005), 
limited research related to the CSM approach has been identified within the literature, aside from a subsequent paper by Calver et al. (2009). The paper of Calver et al. (2009) covers the recommendations of Calver et al. (2005) to quantitatively compare the CSM approach to the event-based FEH procedures. 107 catchments in Great Britain, ranging from 10-1 $200 \mathrm{~km}^{2}$, were considered in the study. In general, the CSM approach (Calver et al., 2005) outperformed the FEH event-based procedures. For example, the 50 -year return period mean and standard deviation of the absolute percentage error between observed and simulated flood peaks were $29 \%$ and $36 \%$, respectively, for the CSM approach, and $39.8 \%$ and $43.6 \%$, respectively, for the FEH event-based procedures.

More recently, Lamb et al. (2016), provides 4 examples of practical situations where a CSM approach was required, due to the inability of the standard FEH methods to adequately address the problems. The benefits of using a CSM approach, many of which are identified above, included the physical nature of the model and increased understanding of hydrological processes used to constrain model parameter uncertainty, explicit representation of antecedent conditions and spatial variations in terms of rainfall and runoff, accounting for climate change and land use change scenarios, explicitly representing flood management operational systems within a CSM, and the ability of the method to provide coherent multivariate flood characteristics. In conclusion, Lamb et al. (2016) highlights that despite the benefits of the approach and the considerable effort placed on developing national procedures, as reviewed above, a comprehensive national scale CSM approach was never developed, i.e., with standardised datasets and the tools required to easily implement the method. Furthermore, no significant effort was made to promote the uptake of the method in practice, which explains why the method remains as a specialist tool to be used only in complex scenarios. Therefore, the critical objective described in Point (ii) above was never achieved.

\section{DESIGN FLOOD ESTIMATION IN AUSTRALIA}

Australian Rainfall and Runoff (ARR) is the national guideline for DFE in Australia (Ball et al., 2016). The first edition of ARR was published in 1958 and has remained one of the most influential and widely used guidelines published by Engineers Australia (Ling et al., 2015). ARR was updated in 1977 and again in 1987/1999, where the 1999 edition is a reprint of the 1987 edition in book form, with only the chapter on the estimation of extreme to large flood events being updated in the 1999 edition. The 1999 edition is often referenced as the 2001 edition, which is simply a reprint of the 1999 edition (Ball et al., 2016). The relatively outdated 1987/1999 edition is currently being revised and updated through 21 research projects to improve on the methodologies used to obtain reliable design flood estimates in Australia (Ball et al., 2016). One of the research projects includes the use of CSM for design flow determination (Project 8), which is reviewed below. The following section, however, contains a review of the primary CSM system for DFE applied practically in Australia (Boughton and Droop, 2003; Ling et al., 2015; Ball et al., 2016), the continuous simulation system (CSS) for DFE.

\section{Continuous simulation system approach}

The CSS for DFE was originally developed by the Cooperative Research Centre for Catchment Hydrology (CRCCH) at
Monash University, Melbourne, Australia. A review of CSM for DFE both within Australia and internationally by Boughton and Droop (2003) is a concise and valuable account of the CS models and methods developed and implemented up to 2003. In addition, Droop (2001) reviewed 12 distributed input CS models and 23 event-based models used for DFE. Consequently, only a brief summary of the reviews done by Boughton and Droop (2003) and Droop (2001) is presented and the focus is on more recent developments.

Boughton et al. (1999) describe the CSS and Boughton et al. (2000) tested the CSS on a number of catchments of medium to small sizes in Victoria, Australia, with further experimentation undertaken by Droop and Boughton (2002), who tested a different flood hydrograph model. The components of the CSS include a stochastic rainfall generator, the simple lumped Australian Water Balance Model (AWBM) and a hydrograph model (Ling et al., 2015). Ling et al. (2015) and Nathan and Ling (2016) summarise the approach and results obtained by Boughton et al. (2000) and Droop and Boughton (2002). Ultimately, design values up to the 2000 -year return period were estimated and the FFC derived from the method are similar to the observed FFC for the more frequent floods, i.e., up to the 20-year return period (Ling et al., 2015). The CSS was also applied in a large $13000 \mathrm{~km}^{2}$, semi-arid catchment in Western Australia by Newton and Walton (2000). Further details on CSM approaches to DFE in Australia are reported by, inter alia, Boughton and Droop (2003); Pathiraja et al. (2012); Ball (2013); Ling et al. (2015); Nathan and Ling (2016); and $\mathrm{Cu}$ (2016). The following section will focus on some of the most recent work regarding CSM techniques within Australia.

\section{ARR Revision Project 8}

Ling et al. (2015) report on the developments in Project 8: Use of Continuous Simulation Models for Design Flood Estimation; in combination with those of Project 12: Selection of an Approach. In summary, the objective of the Ling et al. (2015) revision paper is to investigate and compare the performance of traditional design event (DE) based, Monte Carlo, and CSM approaches to DFE under a range of conditions. For the CSM component of the study, 3 separate simple water balance models, widely tested in Australian conditions, were evaluated on 4 diverse catchments located in various regions across Australia, with an additional catchment added at a later stage. The 5 catchments selected to evaluate the performance of the CSM approaches were a subset of a total of 10 catchments selected to evaluate the performance of the Monte Carlo and DE based approaches (Ling et al., 2015).

The three simple CS rainfall-runoff models used were: (i) the AWBM, as used in the CSS, (ii) the SIMHYD model as detailed by Chiew et al. (2002), and (iii) the GR4H model as detailed by Mathevet (2005); Van Esse et al. (2013) and Bennett et al. (2014). For further details on the models refer to Ling et al. (2015). Stochastic rainfall generation was not used in the study by Ling et al. (2015) since observed input data, i.e., rainfall and potential evapotranspiration, required to simulate stream flow in each of the three models, were available for the same length of available observed flow records for each catchment selected. Furthermore, the objective of the study was to test the ability of the models to reproduce the hydrograph behaviour and the FFC of the observed data and consequently there was no need to stochastically extend the rainfall record. Each of the three models were calibrated to the observed flow data and four different calibration scenarios were investigated, including: 
(i) calibration to all data, (ii) calibration to a subset of the data, (iii) calibration to flows above a threshold, and (iv) calibration to the observed FFC. A global optimisation algorithm called the Shuffled Complex Evolution (SCE) was used to calibrate the parameters of each of the three models (Ling et al., 2015). In general, the GR4H model provided the best results.

In summary, Ling et al. (2015) state that a reasonably good representation of hydrograph behaviour, in conjunction with flood quantiles, was only obtained for one out of the five catchments investigated. Therefore, the study highlighted the inability of the CS models used to reproduce both flood hydrographs and flood quantiles consistently across catchments with varying characteristics. It was noted, however, that reasonable results may be obtained given good quality data and adequate model structure (Ling et al., 2015). The findings suggest that CSM models should be calibrated and or configured in different ways for different assessments, e.g., if a practitioner is mainly interested in the estimation of accurate flood quantiles the calibration results from the above scenario (Scenario iv) should be utilised. If, however, the practitioner is mainly interested in hydrograph behaviour then Scenario (i) should be used. This situation, however, needs to be approached with caution as erroneous results may be obtained when attempting to force a fit. Ultimately, the goal should be to develop models or methodologies that are able to adequately reproduce all aspects of the observed flow data. Therefore, as suggested by Martinez and Gupta (2010) and Ling et al. (2015), model performance should be diagnosed in detail and subsequent improvements or refinements to the model should be made.

\section{ADDITIONAL CONTINUOUS SIMULATION METHODS APPLIED INTERNATIONALLY}

The following sections briefly review some additional CSM studies and CS models currently being applied in other countries.

\section{The United States}

A plethora of CS models have been developed within the United States to date. This section briefly identifies some of the more commonly used CS models applied for DFE in the country. Variations of the Stanford Watershed Model, e.g., the HSPF models, have been used in several studies within the United States for DFE including, inter alia, Soong et al. (2005) and Soong et al. (2009). Furthermore, Boughton and Droop (2003) make note of a modernised version of the Stanford Watershed Model used in the analysis of design floods for urban catchments. The HSPF models, although complex, i.e., with up to 14 parameters to calibrate (Singh et al., 2004), are accepted by the Federal Emergency Agency for use by the National Flood Insurance Program (Soong et al., 2005). The United States Army Corps of Engineers (USACE) Hydrologic Engineering Center - Hydrologic Modelling System (HEC-HMS) is another well-known model, with CSM capabilities, applicable to a wide range of problems for both small urban and natural watersheds. The method has also been used for DFE both in the United States and internationally (Boughton and Droop, 2003; USACE, 2008; Haberlandt and Radtke, 2013; Cu, 2016; USACE, 2016). The Storm Water Management Model (SWMM) developed by USEPA, similar to HEC-HMS, is a dynamic rainfall-runoff simulation model, with CSM capabilities, used to simulate runoff quantity and quality, however, primarily for urban areas (Rossman, 2015). SWMM has also been incorporated into urban drainage models developed in other countries, such as the widely used Danish Hydraulic Institute (DHI), MIKE URBAN software (DHI, 2017). SWMM has also been used for DFE (Ball, 2013; Ahn et al., 2014)

\section{France}

Paquet et al. (2013) describe a probabilistic semi-continuous rainfall-runoff method called Simulation Climato-Hydrologique pourl'Appréciation des Débits EXtrêmes (SCHADEX), developed at Electricité de France (EDF) for the design of dam spillways. Since its development the SCHADEX method has been extensively utilised both within France as well as other European countries, e.g., Norway (Lawrence et al., 2014), for industrial studies, and applied to catchments ranging in size from only a few square kilometres to thousands of square kilometres (Paquet et al., 2013). Paquet et al. (2013) explain that the SCHADEX method has replaced the former Gradient of Extreme Values (GRADEX) method as the official method used by EDF to estimate extreme flood discharges for the design of dams. For further details refer to Paquet et al. (2013).

Paquet et al. (2013) state that the scientific evaluation and development of SCHADEX is ongoing and the method is being compared to other contemporary methods in major projects such as the FloodFreq European Cooperation in Science and Technology (COST) Action (COST, 2013). Several additional CS models are investigated in the FloodFreq European COST Action and a model that is worth mentioning with application to DFE, with considerations of climate change, is the Hydrologiska Byråns Vattenbalansavdelning (HBV) model (Bergström, 1976; Bergström, 1992), with several studies referring to or reporting on experimentation with the HBV model for DFE including, inter alia, COST (2013); Devi et al. (2015) and Zeng et al. (2016).

An additional set of CS models utilised and developed in France includes the GR model series, developed under the stewardship of the National Research Institute of Science and Technology for Environment and Agriculture - IRSTEA (Mouelhi et al., 2013). This includes the GR4H model, as implemented in ARR Revision Project 8, which is an hourly version of the GR4J daily rainfall-runoff model developed by Perrin et al. (2003) with 2 storages and 4 parameters (Van Esse et al., 2013; Bennett et al., 2014). Although not a CSM approach, another noteworthy event-based simulation approach SHYREG, developed over several years, also by IRSTEA, has recently been established as a national DFE method in France (Arnaud et al., 2016; Arnaud et al., 2017; Odry and Arnaud, 2017). Arnaud et al. (2016); Arnaud et al. (2017) and Odry and Arnaud (2017) have compared the SHYREG approach to several other FFA methods applied in the country and highlight several advantages of the approach, including greater stability of the regionalised rainfall-runoff model parameter for different regionalisation methods, in comparison to a regional FFA for example. The method also provides more adequate flood quantiles at higher return periods compared to regionalised statistical approaches including the regional FFA approach: however, it overestimates the lower return period events (Odry and Arnaud, 2017). The SHYREG approach utilises a stochastic hourly rainfall generator to simulate extended rainfall time-series, on an event basis, at any point in France at a $1 \mathrm{~km}$ resolution. The rainfall-runoff model converts this rainfall into a flood quantile at the point, and these point estimates are scaled to the catchment using reduction factors (Odry and Arnaud, 2017). 


\section{Italy}

In Italy the Research Institute for Geo-Hydrological Protection developed a simple semi-distributed CS model, called Modello Idrologico Semi-Distribuito in continuo (MISDc), for flood estimation in the Upper Tiber River (Brocca et al., 2011). The model is composed of two components. The first is a soil water balance model that simulates the soil moisture content over time as a function of rainfall, infiltration, evapotranspiration and drainage and the second is a modified SCS-CN eventbased rainfall-runoff model (MISD). Brocca et al. (2011) calibrated and validated the MISDc model on 3 subcatchments within the Upper Tiber River catchment. Using stochastically generated rainfall and temperature data for a period of 5000 years, Brocca et al. (2011) generated a 5000 -year long flow sequence, from which FFCs were derived. The simulations for each subcatchment were repeated 10 times to account for the uncertainty and variability associated with the stochastically generated rainfall and temperature inputs. The percentage differences between simulated and observed FFCs ranged between 8 and 13\% for the three subcatchments investigated, confirming the reliability of the method for the estimation of design flood discharges. Similar results and findings are presented by Camici et al. (2011). Brocca et al. (2011) also highlight the high computational efficiency of the simple MISDc model and conjoining stochastic models, which allow for rapid, accurate and easily obtainable peak discharge estimates for high return periods.

\section{Austria}

Grimaldi et al. (2012) tested an empirical CS procedure named the Continuous Simulation Model for Small and Ungauged Basins (COSMO4SUB), on the gauged Wattenbach River catchment $\left(71 \mathrm{~km}^{2}\right)$, located in the central eastern Alps, Austria. The method is designed for application to small ungauged catchments, particularly where large-scale regionalised methods are not applicable. The method comprises of a daily rainfall model and disaggregation method to generate synthetic fine-resolution sub-daily rainfall data. Rainfall excess is then estimated using a modified SCS-CN loss model (SCS, 1972), which continuously accounts for antecedent soil moisture using a rainfall separation interval variable $(T)$. An advanced version of the Width-Function Instantaneous Unit Hydrograph (WFIUH) geomorphological rainfall-runoff model is then used to generate complete hydrographs and peak flows. Finally, a FFA is performed on the peak flow time series to derive synthetic design hydrographs (SDHs) (Grimaldi et al., 2012). The method is relatively simple with only 4 parameters to be estimated from the physical attributes and characteristics of the catchment. Grimaldi et al. (2012) state that the model is capable of providing useful results and is able to simulate a range of flood scenarios; however, further investigation, development and improvement of the approach is necessary.

\section{DISCUSSION AND CONCLUSIONS}

In the past few years there has been a high prevalence of flooding both in South Africa and internationally, that has caused extensive damage and resulted in the loss of life (Alexander, 2002; Smithers, 2012; UNISDR, 2015; FloodList, 2016). In addition, the effects of climate change are evident in the alterations identified in both the intensity and frequency of extreme rainfall events (Ndiritu, 2005; Kruger, 2006;
Hrachowitz et al., 2013; Kusangaya et al., 2014; Kruger and Nxumalo, 2017). Consequently, there is a need to modernise, improve and update DFE techniques within South Africa, as outlined in the NFSP. One of the recommendations in the NFSP is further development and assessment of the CSM approach to DFE in South Africa. In addition, the various benefits of a CSM approach to DFE have been highlighted throughout this paper with international as well as local examples.

The CSM approach may be particularly suited to South Africa for the following reasons. In South Africa climate varies significantly across the country, and significant rainfall variability within relatively small areas is common. Therefore, a CSM approach that accounts for spatial differences in rainfall would be beneficial and appropriate in South Africa. In addition, climate change and land use change, which are becoming more and more ubiquitous, throughout the country need to be taken into account, and the CSM approach provides an approach to do this in a conceptually sound manner, where parameters can be changed over different time scales to represent these changes. Furthermore, from an operational management perspective, there are a considerable number of dams, water transfer schemes, abstractions (e.g. irrigation), and additional water infrastructure systems that need to be included in FFA, as seen in the example provided by Lamb et al. (2016). The CSM approach can incorporate these systems into the analysis, and different scenarios can be simulated, thus providing greater confidence in the results. The strong seasonality of rainfall in certain parts of the country, and the wide variety of soil types within the country, also suggest that in many cases antecedent conditions play a significant role in runoff response, and therefore the ability of the CSM approach to explicitly account for such conditions is a significant benefit. The CSM approach also has significant potential for use in flood forecasting, as predicted weather information can be fed into the model to plan for possible flood events before they occur. The forecasting will improve the management of water-related infrastructure, e.g., running scenarios on dam releases prior to a flood to prevent overcapacity of the spillway and to minimise risk. Lastly the ability of the method to provide coherent multivariate flood characteristics is a major advantage.

In the development of a national CSM approach to DFE in South Africa, some important lessons can be learnt from the international literature, including the review of the national CSM system developed for the United Kingdom (Calver et al., 2005). For example, it was highlighted that the CSM approach is often neglected in practice as it is more data intensive, complicated and time consuming to apply compared to simple event-based methods. Calver et al. (2005), therefore, in the development of the national CSM approach, emphasise the importance of using efficient, yet simple, parameter-sparse CS models, since parameters need to be derived indirectly from easily obtainable catchment descriptors. This is supported by the review of CSM for DFE in Australia where simple parameter-sparse models have been developed and applied. The benefit of the ACRU model, however, is that model parameters are not calibrated and transferred to ungauged catchments, instead they are linked to physical catchment characteristics, most of which have been mapped for the country.

The benefit of stochastically generating rainfall time series for use with a CSM system is also highlighted and strongly recommended in the international review. In addition, the benefit of modelling at a sub-daily time step is also highlighted. Therefore, further development, assessment, and inclusion (i.e. within the CSM approach) of daily rainfall 
disaggregation and stochastic rainfall generation techniques is strongly recommended for future research as shown in Table 1. These are, however, individually significant research projects in their own right. Consequently, it is proposed that the initial focus should be on the development of a CSM system (Table 1), with rainfall disaggregation and stochastically generated rainfall (including climate change considerations, predictions and extrapolations) viewed as secondary, complementary research which could easily be incorporated into the CSM approach.

More recently in South Africa, Rowe (2015) investigated a methodology to include land management and hydrological condition classes used in the SCS-SA model into the ACRU land cover classification. Further development and investigation of the approach, however, was recommended, including the analysis of additional land cover classes, further independent verification at different geographical locations, and verification of the simulated results against observed data, in terms of both runoff volumes and peak discharges. In addition, further development of a CSM system or methodology for South Africa was recommended. Confidence in using the SCS-SA classification as a reference, to derive land management practice and hydrological condition classes for use with the ACRU model, is gained through the review of contemporary CSM methods applied internationally, i.e., Italy and Austria, where it was highlighted that the SCS-CN methodology is still widely applied as accepted practice, but it is evident that this sentiment is not unanimous within the literature.
The next section compiles all the information reviewed thus far and summarises a suggested path towards the establishment of a comprehensive CSM approach for DFE in South Africa.

\section{RECOMMENDATIONS FOR SOUTH AFRICA}

Table 1 provides a summary of the steps required to develop and establish a national scale CSM approach for DFE in South Africa. In terms of developing a useable system for practitioners to use, the most critical components from Table 1 are Steps 3 and 4 . As identified from the review of the developments towards a national CSM approach in the UK (Calver et al., 2005), and as highlighted by Lamb et al. (2016), this was the critical step that was not achieved. Therefore, the successful adoption of this approach will rely on the development of a final software tool, with all the necessary inputs and national scale databases required. The initial idea, as alluded to in Table 1, is to base the system (particularly in terms of the user interface and options) on the already widely used SCS-SA event-based approach, which should greatly assist in the adoption of the approach in practice. In addition, while working on the ACRU CS model, it has been proposed to use the results and range of simulation outputs from the ACRU model to update the soil moisture adjustment options in the SCS-SA model. The standard and updated options should be used with the SCS-SA model and comparative studies performed against the optimised ACRU CS model. Additional comparisons with other DFE methods may also be considered and are encouraged in future.

\section{TABLE 1}

\section{Steps required to develop a comprehensive useable CSM approach for DFE in South Africa}

\section{STEP 1}

Further development, validation and verification of the ACRU CS model in terms of:

Input data (climate, soils, land cover), model structure in terms of process representation, and how best to set up or package the model in terms of ease of use, while still providing outputs of high quality and certainty, i.e., level of detail required.

Accurate simulations of both day-to-day flows and extreme values - in terms of volumes, peak discharges (lag time) and complete hydrographs.

The Inclusion of a methodology to account for uncertainty in model parameterisation.

\section{STEP 2}

Further development, assessment and inclusion of national stochastic rainfall generation and/or disaggregation techniques: These methods will introduce the ability to account for uncertainty in model time-series inputs, as well as increase confidence in estimates of high return period events (100 years and above).

The methods should also provide options to estimate projected climate change scenarios, or alternatively an additional set of rainfall models should be established for this. These techniques will be of significant benefit to both the CSM approach as well as other event-based simulation approaches.

\section{STEP 3}

Compiling all these steps and additional models into a user-friendly, simple software tool, that is attractive to consultants and government organisations (e.g. DWS, SANRAL).

Training courses, workshops and user manuals are critical to successful adoption of the approach; however, if the model options are similar to an already widely used tool, i.e., the SCS-SA model, this will greatly facilitate adoption of the approach in practice.

\section{STEP 4}

Continual updating, refinement and improvement of the approach including, for example, flood routing routines and flood forecasting.

Close collaboration between practitioners and model developers (researchers) is needed. 
In addition, it is important to note at this stage that it is the authors' opinion that the ACRU CS model has significant potential, since it has been adapted to South African conditions and has been extensively validated and verified, and is therefore a suitable comprehensive CS model to be used in future studies. There should, however, also be evaluation of the performance of simpler, parameter-sparse CS models for DFE in South Africa.

Therefore, in summary, the potential for using a CSM approach to DFE in South Africa is evident from studies reported in the literature. However, there is still significant development required before a CSM system for DFE can be widely used by practitioners and it is recommended that the steps summarised in Table 1 should be followed.

\section{ACKNOWLEDGEMENTS}

Support for this research by the National Research Foundation (NRF) and University of KwaZulu-Natal (UKZN) is gratefully acknowledged. We also wish to thank the anonymous reviewers for their constructive review comments, which significantly helped to improve the paper.

\section{REFERENCES}

ACOCKS J (1988) Veld types of South Africa. Memoirs of the Botanical Survey of South Africa No. 57. Botanical Research Institute, Pretoria.

AHN J, CHO W, KIM T, SHIN H and HEO J (2014) Flood frequency analysis for the annual peak flows simulated by an event-based rainfall-runoff model in an urban drainage basin. Water $63841-$ 3863. https://doi.org/10.3390/w6123841

ALEXANDER W (2002) Statistical analysis of extreme floods. J. S. Afr. Inst. Civ. Eng. 44 (1) 20-25.

ARNAUD P, CANTET P and ODRY J (2016) SHYREG, a national database of flood frequency estimation. In: 3rd European Conference on Flood Risk Management (FLOODrisk 2016), E3S Web of Conferences, 7, 01004, 17-21 October 2016, Lyon, France. https:// doi.org/10.1016/j.jhydrol.2017.09.011

ARNAUD P, CANTET P and ODRY J (2017) Uncertainties of flood frequency estimation approaches based on continuous simulation using data resampling. J. Hydrol. 554 360-369.

BALL J (2013) Estimation of Design Floods using Continuous Simulation. In: Floodplain Management Australia (FMA) National Conference, 28-31 May 2013, Newcastle, NSW, Australia.

BALL J, BABISTER M, NATHAN R, WEEKS B, WEINMANN E, RETALLICK M, and TESTONI I (2016) Australian Rainfall and Runoff: A Guide to Flood Estimation. Commonwealth of Australia.

BENNETT J, ROBERTSON D, LAL D, WANG Q, ENEVER D, HAPUARACHCHI P and TUTEJA N (2014) A System for continuous hydrological ensemble forecasting (SCHEF) to lead times of 9 days. J. Hydrol. 519 2832-2846. https://doi.org/10.1016/j. jhydrol.2014.08.010

BERGSTRÖM S (1976) Development and application of a conceptual model for Scandinavian catchments. SMHI Report RH07. Swedish Meteorological and Hydrological Institute, Norrkoping, Sweden.

BERGSTRÖM S (1992) The HBV Model - Its Structure and Applications. SMHI Report RH No. 4. Swedish Meteorological and Hydrological Institute, Norrkoping, Sweden.

BEVEN K (1987) Towards the use of catchment geomorphology in flood frequency predictions. Earth Surf. Process. Landforms 12 69-82. https://doi.org/10.1002/esp.3290120109

BLAZKOVA S and BEVEN K (2004) Flood frequency estimation by continuous simulation of subcatchment rainfalls and discharges with the aim of improving dam safety assessment in a large basin in the Czech Republic. J. Hydrol. 292 153-172.

BLAZKOVA S and BEVEN K (2009) A limits of acceptability approach to model evaluation and uncertainty estimation in flood frequency estimation by continuous simulation: Skalka catchment, Czech Republic. Water Resour. Res. 45 (W00B16) 1-12. https://doi. org/10.1016/j.jhydrol.2003.12.025
BLÖSCHL G, SIVAPALAN M, WAGENER T, VIGLIONE A and SAVENIJE H (2013) Runoff Predictions in Ungauged Basins: Synthesis across Processes, Places and Scales, Cambridge University Press, Cambridge. https://doi.org/10.1017/CBO9781139235761

BOUGHTON W and DROOP O (2003) Continuous simulation for design flood estimation-a review. Environ. Model. Softw. 18 309-318. https://doi.org/10.1016/S1364-8152(03)00004-5

BOUGHTON W, MUNCASTER S, SRIKANTHAN R, WEINMANN $P$ and MEIN R (1999) Continuous simulation for design flood estimation - a workable approach. Institution of Engineers, Canberra. 178-183.

BOUGHTON W, SRIKANTHAN R and WEINMANN E (2000) Benchmarking a New Design Flood Estimation System. Institution of Engineers, Canberra. 570-575.

BROCCA L, MELONE F and MORAMARCO T (2011) Distributed rainfall-runoff modelling for flood frequency estimation and flood forecasting. Hydrol. Process. 25 (18) 2801-2813. https://doi. org/10.1002/hyp. 8042

CALVER A (1996) Development and experience of the 'TATE' rainfallrunoff model. Proc. Inst. Civ. Eng. Water Mar. Energ. 118 168-176. https://doi.org/10.1680/iwtme.1996.28684

CALVER A, CROOKS S, JONES D, KAY A, KJELDSEN T and REYNARD N (2004) Flood Frequency Quantification for Ungauged Sites using Continuous Simulation: a UK Approach. Centre for Ecology \& Hydrology (CEH), Wallingford.

CALVER A, CROOKS S, JONES D, KAY A, KJELDSEN T and REYNARD N (2005) National river catchment flood frequency method using continuous simulation. R\&D Technical Report FD2106/TR. Centre for Ecology \& Hydrology (CEH), Wallingford.

CALVER A and LAMB R (1995) Flood frequency estimation using continuous rainfall-runoff modelling. Phys. Chem. Earth 20 (5-6) 479-483. https://doi.org/10.1016/S0079-1946(96)00010-9

CALVER A, LAMB R, KAY A and CREWETT J (2001) The continuous simulation method for river flood frequency estimation. Defra Project FD0404 Final Report. Centre for Ecology \& Hydrology (CEH), Wallingford.

CALVER A, LAMB R and MORRIS S (1999) River flood frequency estimation using continuous runoff modelling. Proc. Inst. Civ. Eng. Water, Maritime Energ. 136 (4) 225-234. https://doi.org/10.1680/ iwtme.1999.31986

CALVER A, STEWART E and GOODSELL G (2009) Comparative analysis of statistical and catchment modelling approaches to river flood frequency estimation. J. Flood Risk Manage. 2 24-31. https:// doi.org/10.1111/j.1753-318X.2009.01018.x

CAMERON D (2006) An application of the UKCIP02 climate change scenarios to flood estimation by continuous simulation for a gauged catchment in the northeast of Scotland, UK (with uncertainty). J. Hydrol. 328 212-226. https://doi.org/10.1016/j.jhydrol.2005.12.024

CAMERON D, BEVEN K, TAWN J, BLAZKOVA S and NADEN P (1999) Flood frequency estimation by continuous simulation for a gauged upland catchment (with uncertainty). J. Hydrol. 219 169-187. https://doi.org/10.1016/S0022-1694(99)00057-8

CAMERON D, BEVEN K, TAWN J and NADEN P (2000) Flood frequency estimation by continuous simulation (with likelihood based uncertainty estimation). Hydrol. Earth Syst. Sci. 4 (1) 23-34. https://doi.org/10.5194/hess-4-23-2000

CAMICI S, TARPANELLI A, BROCCA L, MELONE F and MORAMARCO T (2011) Design soil moisture estimation by comparing continuous and storm-based rainfall-runoff modeling. Water Resour. Res.h 47 (W05527) 1-18.

CHETTY K and SMITHERS J (2005) Continuous simulation modelling for design flood estimation in South Africa: Preliminary investigations in the Thukela catchment. Phys. Chem. Earth $A / B / C$ 30 (11-16) 634-638. https://doi.org/10.1016/j.pce.2005.08.002

CHIEW F, PEEL M and WESTERN A (2002) Application and testing of the simple rainfallrunoff model SIMHYD. In: Singh VP and Frevert DK (eds) Mathematical Models of Small Watershed Hydrology and Applications. Water Resource Publishers, Colorado. 335-367.

CLOTHIER A and PEGRAM G (2002) Space-time modelling of rainfall using the string of beads model: integration of radar and raingauge data. WRC Report No. 1010/1/02. Water Research Commission, Pretoria. 
COST (2013) A Review of Applied Methods in Europe for FloodFrequency Analysis in a Changing Environment. WG4: Flood Frequency Estimation Methods and Environmental Change. COST Action ES0901. Centre for Ecology \& Hydrology, Wallingford.

CRAWFORD N and BURGES S (2004) History of the Stanford Watershed Model. Water Resour. Impact 6 (2) 1-3.

CU T (2016) Enhancement of design flood estimation using continuous simulation. PhD thesis, School of Civil and Environmental Engineering, Faculty of Engineering and Information Technology, University of Technology, Sydney, Australia.

DEVI G, GANASRI B and DWARAKISH G (2015) A Review on hydrological models. Aquat. Procedia 4 1001-1007. https://doi. org/10.1016/j.aqpro.2015.02.126

DHI (2017) Mike Urban - integrated urban water modelling. URL: http://www.mikepoweredbydhi.com/products/mike-urban (Accessed 26 April 2017).

DROOP O (2001) Literature review of distributed modelling. Research Report No. 1/01. Gilbert and Associates, Brisbane, Australia.

DROOP O and BOUGHTON W (2002) Integration of WBNM into a continuous simulation system for design flood estimation, Research Report No. 2/02. Gilbert and Associates, Brisbane, Australia.

DU PLESSIS J and BURGER G (2015) Investigation into increasing short-duration rainfall intensities in South Africa. Water SA 41 (3) 416-424. https://doi.org/10.4314/wsa.v41i3.14

FLOODLIST (2016) FloodList - Reporting floods and flooding news since 2008. URL: http://www.floodlist.com (Accessed 20 September 2016 2016).

FREZGHI M (2005) The development and assesment of a methodology to improve the estimation of the spatial distribution of rainfall. MSc thesis, School of Bioresources Engineering and Environmental Hydrology, University of KwaZulu-Natal, Pietermaritzburg, South Africa.

GERICKE O and SMITHERS J (2014) Review of methods used to estimate catchment response time for the purpose of peak discharge estimation. Hydrol. Sci. J. 59 (11) 1935-1971. https://doi. org/10.1080/02626667.2013.866712

GERICKE O and SMITHERS J (2016) Derivation and verification of empirical catchment response time equations for medium to large catchments in South Africa. Hydrol. Process. 30 4384-4404.

GERICKE O and SMITHERS J (2017) Direct estimation of catchment response time parameters in medium to large catchments using observed streamflow data. Hydrol. Process. 31 (5) 1125-1143. https://doi.org/10.1002/hyp.11102

GERICKE O and SMITHERS J (2018) An improved and consistent approach to estimate catchment response time parameters: Case study in the C5 drainage region, South Africa. J. Flood Risk Manage. 11 (S1) S284-S301. https://doi.org/10.1111/jfr3.12206

GÖRGENS A (2007) Joint Peak-Volume (JPV) Design Flood Hydrographs for South Africa. WRC Report No 1420/3/07. Water Research Commission, Pretoria.

GRIMALDI S, PETROSELLI A and SERINALDI F (2012) A continuous simulation model for design-hydrograph estimation in small and ungauged watersheds. Hydrol. Sci. J. 57 (6) 1035-1051. https://doi.org/10.1080/02626667.2012.702214

HABERLANDT U and RADTKE I (2013) Derived flood frequency analysis using different model calibration strategies based on various types of rainfall-runoff data - a comparison. Hydrol. Earth Syst. Sci. 10 (8) 10379-10417. https://doi.org/10.5194/ hessd-10-10379-2013

HABERLANDT U and RADTKE I (2014) Hydrological model calibration for derived flood frequency analysis using stochastic rainfall and probability distributions of peak flows. Hydrol. Earth Syst. Sci. 18 (1) 353-365. https://doi.org/10.5194/ hess-18-353-2014

HRACHOWITZ M, SAVENIJE H, BLÖSCHL G, MCDONNELL J, SIVAPALAN M, POMEROY J, ARHEIMER B, BLUME T, CLARK M, EHRET U, FENICIA F, FREER J, GELFAN A, GUPTA H, HUGHES D, HUT R, MONTANARI A, PANDE S, TETZLAFF D, TROCH P, UHLENBROOK S, WAGENER T, WINSEMIUS H, WOODS R, ZEHE E and CUDENNEC C (2013) A decade of Predictions in Ungauged Basins (PUB)-a review. Hydrol. Sci. J. 58 (6) 1198-1255. https://doi.org/10.1080/02626667.2013.803183 INSTITUTE OF HYDROLOGY (1999) Flood Estimation Handbook
(5 volumes). Institute of Hydrology, Wallingford.

KANG M, GOO J, SONG I, CHUN J, HER Y, HWANG S and PARK $S$ (2013) Estimating design floods based on the critical storm duration for small watersheds. J. Hydro-environ. Res. 7 209-218.

KJELDSEN T (2007) The Revitalised FSR/FEH Rainfall-Runoff Method. Flood Estimation Handbook, Supplementary Report No. 1. Centre for Ecology \& Hydrology (CEH), Wallingford, United Kingdom.

KJELDSEN T (2015) How reliable are design flood estimates in the UK? J. Flood Risk Manage. 8 (3) 237-246. https://doi.org/10.1111/ jfr3.12090

KNOESEN D (2005) The development and assessment of techniques for daily rainfall disaggregation in South Africa. MSc thesis, School of Bioresources Engineering and Environmental Hydrology, University of KwaZulu-Natal, Pietermaritzburg, South Africa.

KNOESEN D and SMITHERS J (2009) The development and assessment of a daily rainfall disaggregation model for South Africa. Hydrol. Sci. J. 54 (2) 217-233. https://doi.org/10.1623/ hysj.54.2.217

KRUGER A (2006) Observed trends in daily precipitation indices in South Africa: 1910-2004. Int. J. Climatol. 26 2275-2285. https:// doi.org/10.1002/joc. 1368

KRUGER A and NXUMALO M (2017) Historical rainfall trends in South Africa: 1921-2015. Water SA 43 (2) 285-297. https://doi. org/10.4314/wsa.v43i2.12

KUSANGAYA S, WARBURTON M, ARCHER VAN GARDEREN E and JEWITT G (2014) Impacts of climate change on water resources in southern Africa: A review. Phys. Chem. Earth $A / B / C$ 67-69 47-54. https://doi.org/10.1016/j.pce.2013.09.014

LAMB R (1999) Calibration of a conceptual rainfall-runoff model for flood frequency estimation by continuous simulation. Water Resour. Res. 35 (10) 3103-3114. https://doi. org/10.1029/1999WR900119

LAMB R, FAULKNER D, WASS P and CAMERON D (2016) Have applications of continuous rainfall-runoff simulation realized the vision for process-based flood frequency analysis? Hydrol. Process. 30: 2463-2481. https://doi.org/10.1002/hyp.10882

LAWRENCE D, PAQUET E, GAILHARD J and FLEIG A (2014) Stochastic semi-continuous simulation for extreme flood estimation in catchments with combined rainfall-snowmelt flood regimes. Nat. Hazards Earth Syst. Sci. 14 1283-1298. https://doi. org/10.5194/nhess-14-1283-2014

LING F, POKHREL P, COHEN W, PETERSON J, BLUNDY S and ROBINSON K (2015) Revision Project 8: Use of continuous simulation models for design flood estimation, Revision Project 12: Selection of an approach. Stage 3 Report, ARR Report Number P12/S3/008. Engineers Australia, Barton, Australia.

MARTINEZ G and GUPTA H (2010) Toward improved identification of hydrological models : A diagnostic evaluation of the "abcd" monthly water balance model for the conterminous United States. Water Resour. Res. 46 1-21. https://doi.org/10.1029/2009WR008294

MATHEVET T (2005) Which global rainfall-runoff models in an hourly time-step? Development and empirical comparison of models on a large sample of watersheds. PhD thesis, AgroParisTech, Paris, France.

MOORE R (1985) The probability-distributed principle and runoff production at point and basin scales. Hydrol. Sci. J. 30 (2) 273-297. https://doi.org/10.1080/02626668509490989

MOUELHI S, MADANI K and LEBDI F (2013) A structural overview through GR(s) models characteristics for better yearly runoff simulation. Open J. Mod. Hydrol. 3 179-187. https://doi. org/10.4236/ojmh.2013.34022

NATHAN R and BALL J (2016) Approaches to flood estimation. Book 1, Chapter 3. In: Ball J, Babister M, Nathan R, Weeks B, Weinmann E, Retallick M and Testoni I (eds) Australian Rainfall and Runoff: A Guide to Flood Estimation. Commonwealth of Australia.

NATHAN R and LING F (2016) Types of simulation approaches. Book 4, Chapter 3. In: Ball J, Babister M, Nathan R, Weeks B, Weinmann E, Retallick M, and Testoni I (eds) Australian Rainfall and Runoff: A Guide to Flood Estimation. Commonwealth of Australia.

NATHAN R and WEINMANN E (2013) Discussion paper: Monte Carlo simulation techniques. Final Report AR\&R D2. Engineers Australia, Barton, Australia. 
NDIRITU J (2005) Long-term trends of heavy rainfall in South Africa. In: Regional Hydrological Impacts of Climatic Change - Hydroclimatic Variability (Proceedings of Symposium S6 held during the Seventh IAHS Scientific Assembly), 3-9 April 2005, Foz do Iguaçu, Brazil.

NERC (1975) Flood studies report. NERC, London.

NEWTON D and WALTON R (2000) Continuous simulation for design flood estimation in the Moore River Catchment, Western Australia. In: Hydro 2000 Hydrology and Water Resources Symposium, 20-23 November 2000, Perth, Australia.

ODRY J and ARNAUD P (2017) Comparison of flood frequency analysis methods for ungauged catchments in France. Geosciences 7 (3) 88. https://doi.org/10.3390/geosciences7030088

PAQUET E, GARAVAGLIA F, GARCON R and GAILHARD J (2013) The SCHADEX method: A semi-continuous rainfall-runoff simulation for extreme flood estimation. J. Hydrol. 495 23-37. https://doi.org/10.1016/j.jhydrol.2013.04.045

PATHIRAJA S, WESTRA S and SHARMA A (2012) Why continuous simulation? The role of antecedent moisture in design flood estimation. Water Resour. Res. 48 (6) W06534 (06531-06515).

PERRIN C, MICHEL C and ANDRÉASSIAN V (2003) Improvement of a parsimonious model for streamflow simulation. J. Hydrol. 279 275-289. https://doi.org/10.1016/S0022-1694(03)00225-7

PITMAN W (2011) Overview of water resource assessment in South Africa: Current state and future challenges. Water SA 37 (5) 659-664. https://doi.org/10.4314/wsa.v37i5.3

ROGGER M, KOHL B, PIRKL H, VIGLIONE A, KOMMA J, KIRNBAUER R, MERZ R and BLÖSCHL G (2012) Runoff models and flood frequency statistics for design flood estimation in Austria - Do they tell a consistent story? J. Hydrol. 456-457 30-43. https:// doi.org/10.1016/j.jhydrol.2012.05.068

ROSSMAN L (2015) Storm Water Management Model User's Manual Version 5.1. EPA- 600/R-14/413b. United States Environmental Protection Agency, Cincinnati.

ROWE T (2015) Development and assessment of rules to parameterise the ACRU model for design flood estimation. MSc thesis, Centre for Water Resources Research, University of KwaZulu-Natal, Pietermaritzburg.

SANRAL (2013) Drainage Manual (Sixth Edition). SANRAL, Pretoria. SCHMIDT E and SCHULZE R (1987) Flood volume and peak discharge from small catchments in southern Africa, based on the SCS technique. WRC Report No. TT 31/87. Water Research Commission, Pretoria.

SCHULZE R (1995) Hydrology and agrohydrology: A text to accompany the ACRU 3.00 agrohydrological modelling system. WRC Report No. TT 69/95. Water Research Commission, Pretoria.

SCHULZE R, SCHMIDT E and SMITHERS J (2004) PC-based SCS design flood estimates for small catchments in Southern Africa. ACRUcons Report No. 52 - Visual SCS-SA User Manual, Version 1. University of KwaZulu-Natal, Pietermaritzburg.

SOIL CONSERVATION SERVICE (1956) Hydrology National Engineering Handbook. Supplement A, Section 4. Soil Conservation Service, US Department of Agriculture, Washington, DC.

SCS (Soil Conservation Service) (1972) National Engineering Handbook, Section 4. Soil Conservation Service, US Department of Agriculture, Washington, DC.

SHARMA A, SRIKANTHAN R, MEHROTRA R, WESTRA S and LAMBERT M (2016) Continuous rainfall simulation. Book 2, Chapter 7. In: Ball J, Babister M, Nathan R, Weeks B, Weinmann E, Retallick M, and Testoni I (eds) Australian Rainfall and Runoff: A Guide to Flood Estimation. Commonwealth of Australia.

SINGH J, KNAPP H and DEMISSIE M (2004) Hydrologic modeling of the Iroquois River Watershed Using HSPF and SWAT. Illinois State Water Survey Contract Report 2004-08. Illinois Department of Natural Resources and Illinois State Geological Survey, Illinois, United States.

SIVAPALAN M, BLÖSCHL G, MERZ R and GUTKNECHT D (2005) Linking flood frequency to long-term water balance: Incorporating effects of seasonality. Water Resour. Res. 41 (6) W06012 1-17.

SMITHERS J (2012) Review. Methods for design flood estimation in South Africa. Water SA 38 (4) 633-646. https://doi.org/10.4314/wsa. v38i4.19

SMITHERS J, CHETTY K, FREZGHI M, KNOESEN D and TEWOLDE M (2007) Development and assessment of a continuous simulation modelling system for design flood estimation. WRC Report No. 1318/1/07. Water Research Commission, Pretoria.

SMITHERS J, CHETTY K, FREZGHI M, KNOESEN D and TEWOLDE M (2013) Development and assessment of a daily time-step continuous simulation modelling approach for design flood estimation at ungauged locations: ACRU model and Thukela Catchment case study. Water SA 30 (4) 467-476. https://doi. org/10.4314/wsa.v39i4.4

SMITHERS J, GÖRGENS A, GERICKE J, JONKER V and ROBERTS C (2016) The initiation of a national flood studies programme for South Africa. South African National Committee on Large Dams, Pretoria, South Africa.

SMITHERS J, PEGRAM G and SCHULZE R (2002) Design rainfall estimation in South Africa using Bartlett-Lewis rectangular pulse rainfall models. J. Hydrol. 258 83-89. https://doi.org/10.1016/ S0022-1694(01)00571-6

SMITHERS J and SCHULZE R (2000) Development and evaluation of techniques for estimating short duration design rainfall in South Africa. WRC Report No. 681/1/00. Water Research Commission, Pretoria.

SMITHERS J and SCHULZE R (2004) ACRU Agrohydrological Modelling System. User Manual Version 4, School of Bioresources Engineering and Environmental Hydrology, University of KwaZulu-Natal, Pietermaritzburg, South Africa.

SMITHERS J, SCHULZE R and KIENZLE S (1997) Design flood estimation using a modelling approach. In: Rosbjerg D, Boutayeb N, Gustard A, Kundzewicz ZW, Rasmussen PF (eds) Sustainability of Water Resources Under Increasing Uncertainty. The International Association of Hydrological Sciences Publication 240. 365-376.

SMITHERS J, SCHULZE R and PEGRAM G (2000) Using stochastically generated rainfall series to estimate short duration design rainfalls in South Africa. Agric. Eng. S. Afr. 23 (1) 109-113.

SMITHERS J, SCHULZE R, PIKE A and JEWITT G (2001) A hydrological perspective of the February 2000 floods: A case study in the Sabie River catchment. Water SA 27 (3) 325-332. https://doi. org/10.4314/wsa.v27i3.4975

SOONG D, MURPHY E and STRAUB T (2009) Effect of detention basin release rates on flood flows - application of a model to the Blackberry Creek Watershed in Kane County, Illinois. USGS Scientific Investigations Report 2009-5106. United States Geological Survey, Virginia, United States.

SOONG D, STRAUB T and MURPHY E (2005) Continuous hydrologic simulation and flood-frequency, hydraulic, and flood-hazard analysis of the Blackberry Creek Watershed, Kane County, Illinois. Scientific Investigations Report 2005-5270. United States Geological Survey, Virginia, United States.

UNISDR (United Nations Office for Disaster Risk Reduction) (2015) The human cost of weather-related disasters 1995-2015. UNISDR, Geneva, Switzerland.

USACE (United States Army Corps of Engineers) (2008) Hydrologic Modeling System HEC-HMS User's Manual Version 3.3. User's Manual version 3.3. USACE, Davis, CA.

USACE (United States Army Corps of Engineers) (2016) Hydrologic Modeling System HEC-HMS User's Manual Version 4.2. User's Manual version 4.2, USACE, Davis, CA.

VAN BILJON S (2000) Flood characteristics at selected sites and operation of reservoirs during the February 2000 Floods. Southern Africa Floods of February 2000. Department of Civil Engineering, University of Pretoria, Pretoria, South Africa.

VAN BLADEREN D and VAN DER SPUY D (2000) The February 2000 flood - the worst in living memory? Southern Africa Floods of February 2000. Department of Civil Engineering, University of Pretoria, Pretoria, South Africa.

VAN ESSE W, PERRIN C, BOOIJ M, AUGUSTIJN D, FENICIA F, KAVETSKI D and LOBLIGEOIS F (2013) The influence of conceptual model structure on model performance: a comparative study for 237 French catchments. Hydrol. Earth Syst. Sci. 17 4227-4239. https://doi.org/10.5194/hess-17-4227-2013

VAN VUUREN S, VAN DIJK M and COETZEE G (2013) Status review and requirements of overhauling flood determination methods in South Africa. WRC Report No. TT 563/13. Water Research Commission, Pretoria.

VOGEL RM (2017) Stochastic watershed models for hydrologic risk 
management. Water Security 1 28-35. https://doi.org/10.1016/j. wasec.2017.06.001

WEINMANN P, RAHMAN A, HOANG T, LAURENSON E and NATHAN R (2002) Monte Carlo simulation of flood frequency curves from rainfall - the way ahead. Aus. J. Water Resour. 6 (1) 71-80.

WESSELS P and ROOSEBOOM A (2009) Flow-gauging structures in South African rivers Part 1 - An overview. Water SA 35 (1) 1-9. WHS (Wallingford HydroSolutions) (2016) The Revitalised Flood Hydrograph Model ReFH 2.2: Technical Guidance. Wallingford
HydroSolutions Ltd, Wallingford, United Kingdom.

WRA (Water Resource Associates) (2018) Water Resource Associates -

HYSIM. URL: http://www.watres.com/software/HYSIM/ (Accessed 4 May 2018).

ZENG Q, CHEN H, XU C, JIE M and HOU Y (2016) Feasibility and uncertainty of using conceptual rainfall-runoff models in design flood estimation. Hydrol. Res. 47 (4) 701-717.

ZUCCHINI W, ADAMSON P and MCNEILL L (1992) A model of Southern African rainfall. S. Afr. J. Sci. 88 (2) 103-109. 